\title{
Detection of chromosome aberrations in the human interphase nucleus by visualization of specific target DNAs with radioactive and non-radioactive in situ hybridization techniques: diagnosis of trisomy 18 with probe $\mathbf{L 1 . 8 4}$
}

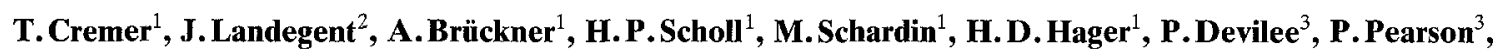 \\ and M.van der Ploeg ${ }^{2}$ \\ ${ }^{1}$ Institut für Anthropologie und Humangenetik der Universität, Im Neuenheimer Feld 328, D-6900 Heidelberg, Federal Republic of Germany \\ ${ }^{2}$ Department of Histochemistry and Cytochemistry and ${ }^{3}$ Department of Human Genetics, Sylvius Laboratories, State University, \\ NL-2333 AL Leiden, The Netherlands
}

\begin{abstract}
Summary. The localization of chromosome 18 in human interphase nuclei is demonstrated by use of radioactive and nonradioactive in situ hybridization techniques with a DNA clone designated L1.84. This clone represents a distinct subpopulation of the repetitive human alphoid DNA family, located in the centric region of chromosome 18 . Under stringent hybridization conditions hybridization of $\mathrm{L} 1.84$ is restricted to chromosome 18 and reflects the number of these chromosomes present in the nuclei, namely, two in normal diploid human cells and three in nuclei from cells with trisomy 18 . Under conditions of low stringency, cross-hybridization with other subpopulations of the alphoid DNA family occurs in the centromeric regions of the whole chromosome complement, and numerous hybridization sites are detected over interphase nuclei. Detection of chromosome-specific target DNAs by non-radioactive in situ hybridization with appropriate DNA probes cloned from individual chromosomal subregions presents a rapid means of identifying directly numerical or even structural chromosome aberrations in the interphase nucleus. Present limitations and future applications of interphase cytogenetics are discussed.
\end{abstract}

\section{Introduction}

Diagnosis of numerical chromosome aberrations so far has been based mainly on the evaluation of mitotic chromosome complements. Only occasionally, specific staining of the constitutive heterochromatin of individual chromosomes $1,9, \mathrm{X}$ and $\mathrm{Y}$, has been used to detect the number or the position of these individual chromosomes in interphase nuclei (Hoehn and Martin 1973; Schmid et al. 1981; Spaeter 1975).

Recently, it has become possible to localize individual human chromosomes in interphase nuclei by in situ hybridization with cloned DNA probes detecting specific repetitive target DNAs (Rappold et al. 1984b). In this paper we demonstrate the localization of the chromosomes 18 in human in-

Offprint requests to: T. Cremer, Institut für Anthropologie und Humangenetik der Universität, Im Neuenheimer Feld 328, D-6900 Heidelbetg, Federal Republic of Germany terphase nuclei from both normal cells and cells with trisomy 18. In situ hybridization experiments were performed using a radioactively and non-radioactively labelled fragment from the human alphoid repetitive DNA family designated L1.84. Under appropriate conditions of stringency, hybridization is mainly restricted to the centromeric region of chromosome 18 (Devilee et al. 1986a, b), and accordingly the number of major hybridization sites reflects the number of chromosomes 18 present in interphase nuclei. However, under less stringent conditions, hybridization occurs at the pericentromeric regions of the whole chromosome complement and numerous hybridization sites are detected over interphase nuclei.

\section{Material and methods}

\section{Cells and metaphase spreads}

Phytohemagglutinin(PHA)-stimulated lymphocyte cultures were established from the blood of a healthy male. Cells with trisomy 18 were obtained from an amniotic-fluid cell culture after amniocentesis at the 17 th week of pregnancy.

Chromosome preparations were made according to standard procedures, including fixation with methanol/acetic acid $(3: 1)$. In some experiments, lymphocytes were cultured in the presence of 5-bromo-2'-deoxyuridine (BrdUrd, $10 \mu \mathrm{g} / \mathrm{ml}$ ) and 5-fluoro-2'-deoxyuridine (FdUrd, $0.5 \mu \mathrm{g} / \mathrm{ml}$ ) for $6 \mathrm{~h}$ before harvesting. The Hoechst-Giemsa technique was used after in situ hybridization (see below) for differential staining of mitotic chromosomes (Schempp and Meer 1983; Zabel et al. 1983).

\section{Preparations of DNA probe L1.84}

L1.84 is a human DNA fragment cloned in the plasmid pAT153. It is $684 \mathrm{bp}$ long and represents a variant of the human alphoid DNA repeat with an estimated copy number of about 2000 per haploid genome (Devilee et al. 1986a). Plasmid DNA containing the L1.84 insert was purified and either nicktranslated with ${ }^{3} \mathrm{H}$ dTTP (Rappold et al. 1984a) or with biotin-11-dUTP (Schardin et al. 1985) or modified with aminoacetylfluorene (AAF) (Landegent et al. 1984). 


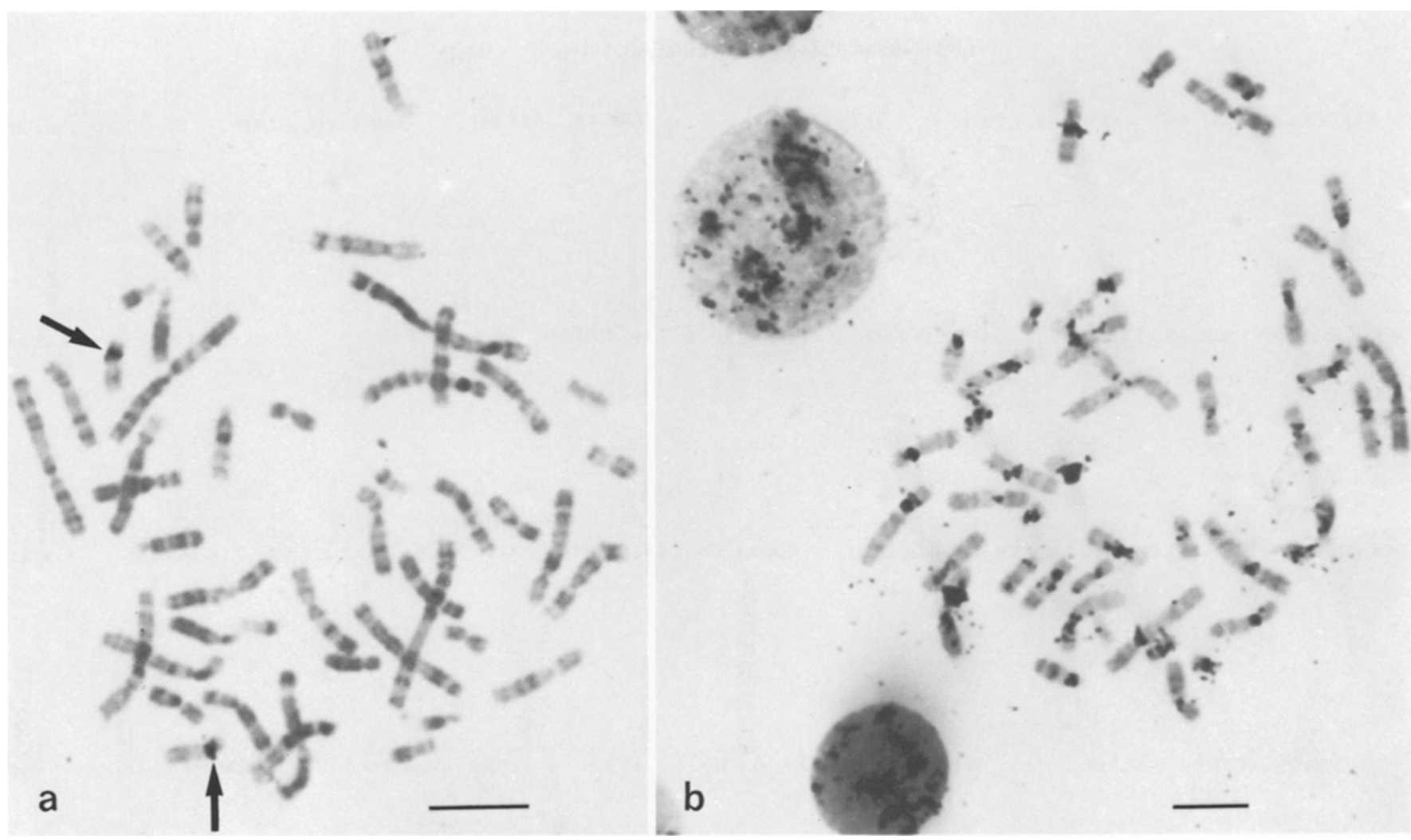

Fig.1a,b. Metaphase spreads from male human lymphocytes with R-type replication pattern after in situ hybridization with ${ }^{3} \mathrm{H}-\mathrm{labelled} \mathrm{DNA}$ probe L1.84 and autoradiography. Bar $=5 \mu \mathrm{m}$. a Metaphase spread obtained after in situ hybridization under conditions of high stringency (see Materials and methods, procedure I). Specific labelling was restricted to the pericentromeric heterochromatin of both chromosomes 18 under these conditions (arrows; compare Fig. 2a). In the specimen the pale blue and dark red stained bands can easily be discriminated from the black clusters of silver grains. b Metaphase spread obtained after in situ hybridization under conditions of low stringency (see Materials and methods, procedure II). Note significant label over the pericentromeric heterochromatin of most chromosomes (compare Fig. 2b)

\section{In situ hybridization and stringency conditions}

In situ hybridization experiments were carried out (1) with ${ }^{3} \mathrm{H}$ dTTP-labelled L1.84 as described by Rappold et al. (1984a), (2) with biotinylated L1.84 as described by Schardin et al. (1985), and (3) with AAF-modified L1.84 as described by Landegent et al. (1984). Between 1.5 and $3 \mu$ lof hybridization mixture was applied per square centimeter of the slides, using a final probe concentration between 1 and $1.5 \mu \mathrm{g} / \mathrm{ml}$.

In some experiments with ${ }^{3} \mathrm{H}$-dTTP-labelled and biotinylated probes, the L1.84 hybridization mixture and washing procedures were adjusted so that the conditions varied from lower to higher stringency. In general, the stringency can be increased by increasing the formamide concentration and/or by decreasing the salt concentration, as well as by raising the temperature of the hybridizations and washing solutions.

In all experiments with a ${ }^{3} \mathrm{H}$-labelled $\mathrm{L} 1.84$ probe, the hybridization mixture as described by Rappold et al. (1984a) was used (with 50\% formamide) and the stringency was altered by different washing conditions. The washing procedure for higher stringency (procedure I) included three washes for $30 \mathrm{~min}$ in formamide: $2 \times \mathrm{SSC}$ (SSC: $150 \mathrm{~m} M$ sodium chloride, $15 \mathrm{mM}$ sodium citrate, $\mathrm{pH} 7), 1: 1,30^{\circ} \mathrm{C}$ and three washes for $5 \mathrm{~min}$ in $2 \times \mathrm{SSC}$ at room temperature. For the lower stringency conditions (procedure II), the slides were washed three times for $30 \mathrm{~min}$ in $2 \times \mathrm{SSC}$ at $30^{\circ} \mathrm{C}$ and three times for $5 \mathrm{~min}$ in $2 \times \mathrm{SSC}$ at room temperature.
In the experiments with biotin-labelled DNA probe, the stringency was varied by changing the formamide concentration of the hybridization mixture. The mixture of higher stringency (mixture I) contained $50 \%$ formamide and $2 \times$ SSC, whereas a mixture II with only $30 \%$ formamide resulted in lower stringency conditions.

\section{Detection of hybridized L1.84}

Detection of hybridization sites of ${ }^{3} \mathrm{H}$-dTTP-labelled probe L1.84 was achieved by autoradiography (Rappold et al. 1984a). The hybridization sites of biotinylated L1.84 were visualized either by the Bethesda Research Laboratories (BRL) DNA detection system no. 8239A (Schardin et al. 1985) or by the double antibody fluorescent system DETEK I-f, supplied by ENZO as described later in this article.

After hybridization and washing, the slides were rinsed for $5 \mathrm{~min}$ in each of the following solutions: $1 \times$ PBS $(140 \mathrm{mM}$ sodium chlorid, $10 \mathrm{~m} M$ sodium phosphate, $\mathrm{pH} 7$ ), $1 \times$ PBS + $0.1 \%$ Triton $\times 100,1 \times$ PBS. The first antibody, IgG fraction rabbit anti-biotin, was diluted 1:100 in PBS containing $0.2 \%$ bovine serum albumine, applied to the slide, and incubated for $1 \mathrm{~h}$ at $37^{\circ} \mathrm{C}$ in a moist chamber. Following three washes for 5 min in PBS, the slides were incubated with the second antibody, FITC-conjugated IgG fraction goat anti-rabbit diluted, and applied as the first antibody. Slides were rinsed three times in PBS and counterstained with DAPI. 


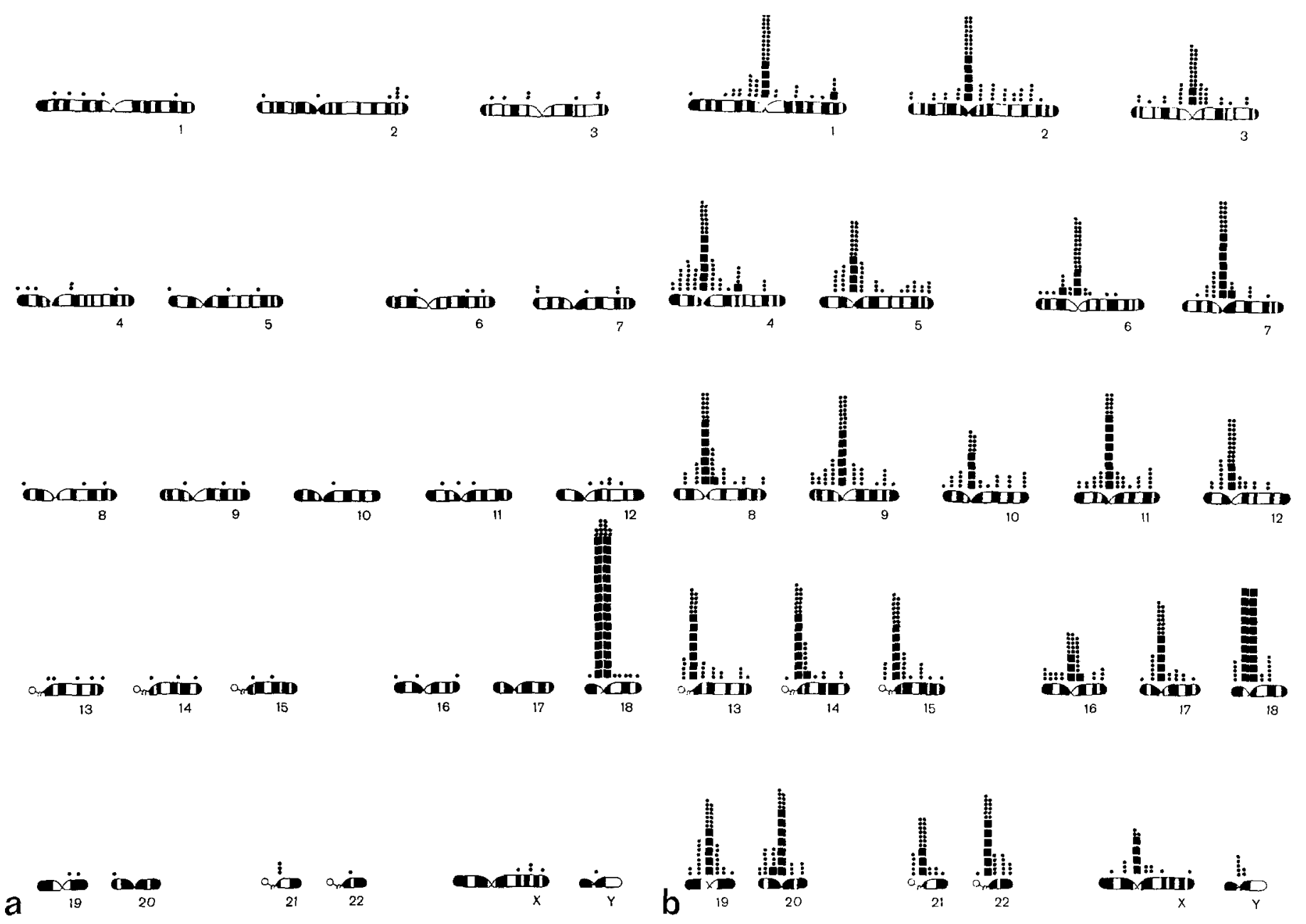

Fig. 2a,b. Histograms of the silver grain distribution on chromosomes from male human lymphocytes (46,XY) evaluated after in situ hybridization with ${ }^{3} \mathrm{H}$-labelled DNA probe L1.84 under conditions of high stringency (a; see Materials and methods, procedure I) and conditions of low stringency (b; see Materials and methods, procedure II), compare Fig. 1a, b. Large dots indicate clusters of silver grains; small dots indicate individual silver grains. Numbers of evaluated metaphase plates were 16 for $\mathbf{a}$ and 10 for $\mathbf{b}$

AAF-modified probe L1.84 was detected by the immunoperoxidase method as described in detail by Landegent et al. (1985). Stained slides were viewed by reflection contrast microscopy (Landegent et al. 1985).

\section{Results}

In situ hybridization experiments were performed with ${ }^{3} \mathrm{H}$ labelled, biotinylated and aminoacetylfluorene (AAF)-modified DNA probe L1.84. All procedures gave apparently identical results. Under conditions of high stringency, hybridization signals were mostly restricted to the centromeric beterochromatin of chromosome 18 . Thus, two strongly labelled chromosomes 18 were obtained in metaphase spreads from diploid male human lymphocytes (Fig. 1a), while three such chromosomes were detected in metaphase spreads from cells with trisomy 18 (Figs. 3a, 4a). Hybridization signals from other chromosomes were weak or absent under these conditions (Fig. 2a).

Accordingly, the number of major hybridization signals observed over interphase nuclei under conditions of high stringency was mostly two in normal diploid nuclei (Fig. 5b) and three in interphase nuclei from trisomic cells (Figs. 3b, c, $4 \mathrm{~b}$ ). These major hybridization signals could be discriminated from minor hybridization signals on other interphase chromosomes by virtue of their considerably larger size and - in case of non-radioactive in situ hybridization - their higher staining intensity. The validity of this discrimination was tested by blind evaluation of diploid cells and cells with trisomy 18 . While populations of interphase nuclei from a diploid and a trisomic amniotic fluid cell culture could be unequivocally identified by several independent investigators, the unequivocal designation of diploid and trisomic cells was not possible in each individual cell nucleus. Due to some inevitable variation in the size and intensity of both major and minor hybridization signals, the number of major signals counted in individual cell nuclei occasionally deviated from the expected number (Fig. 6). While it might be possible to improve these protocols further, it should be noted that it is intrinsically difficult to control the factors involved in the variation of the signals rigidly. For example, loss of target DNAs may vary in different cell nuclei of the same slide and even in different chromosomes of an individual nucleus. Under conditions of low stringency, hybridization signals were obtained over the pericentromeric regions of all chromosomes in metaphase 


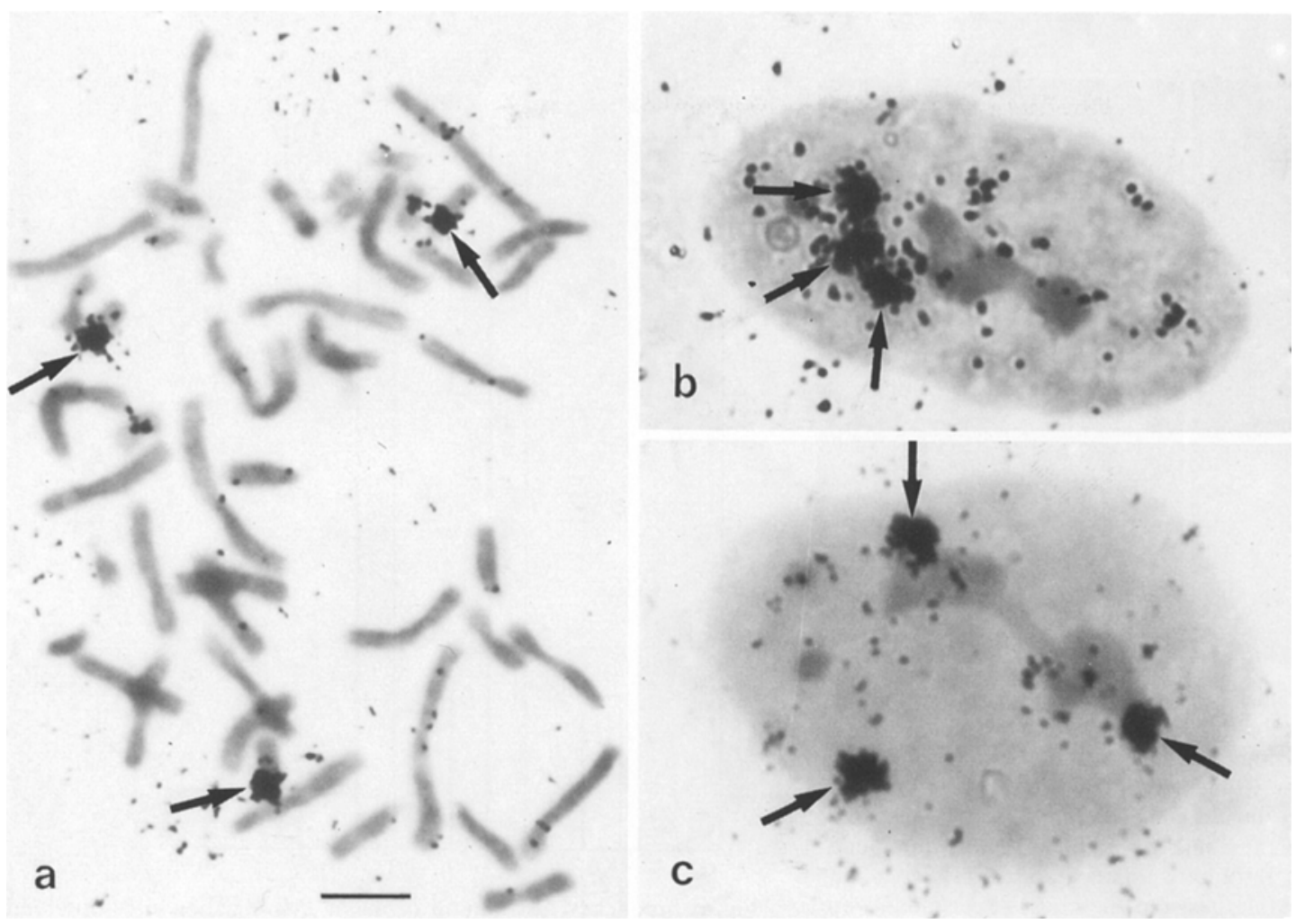

Fig.3a-c. Metaphase spread (a) and interphase nuclei $(\mathbf{b}, \mathbf{c})$ from an amniotic fluid cell culture with trisomy 18 after in situ hybridization with ${ }^{3} \mathrm{H}$-labelled DNA probe L1.84 under conditions of higher stringency (see Materials and methods, procedure I) autoradiography and Giemsa staining. Bar $=5 \mu \mathrm{m}$. Arrows in a indicate large clusters of silver grains over the pericentric heterochromatin of the three chromosomes 18; arrows in $\mathbf{b}, \mathbf{c}$ show three silver grain clusters of corresponding size in interphase nuclei. Note the variability of the interphase positions of the three chromosomes 18 marked by the silver grain clusters. A closer inspection of other silver grains in a indicates that these silver grains are preferably localized over the pericentromeric heterochromatin of other chromosomes, although these minor hybridization signals were not observed in the experiment shown in Figs. 1a and 2a using BrdUrd-substituted chromosomes
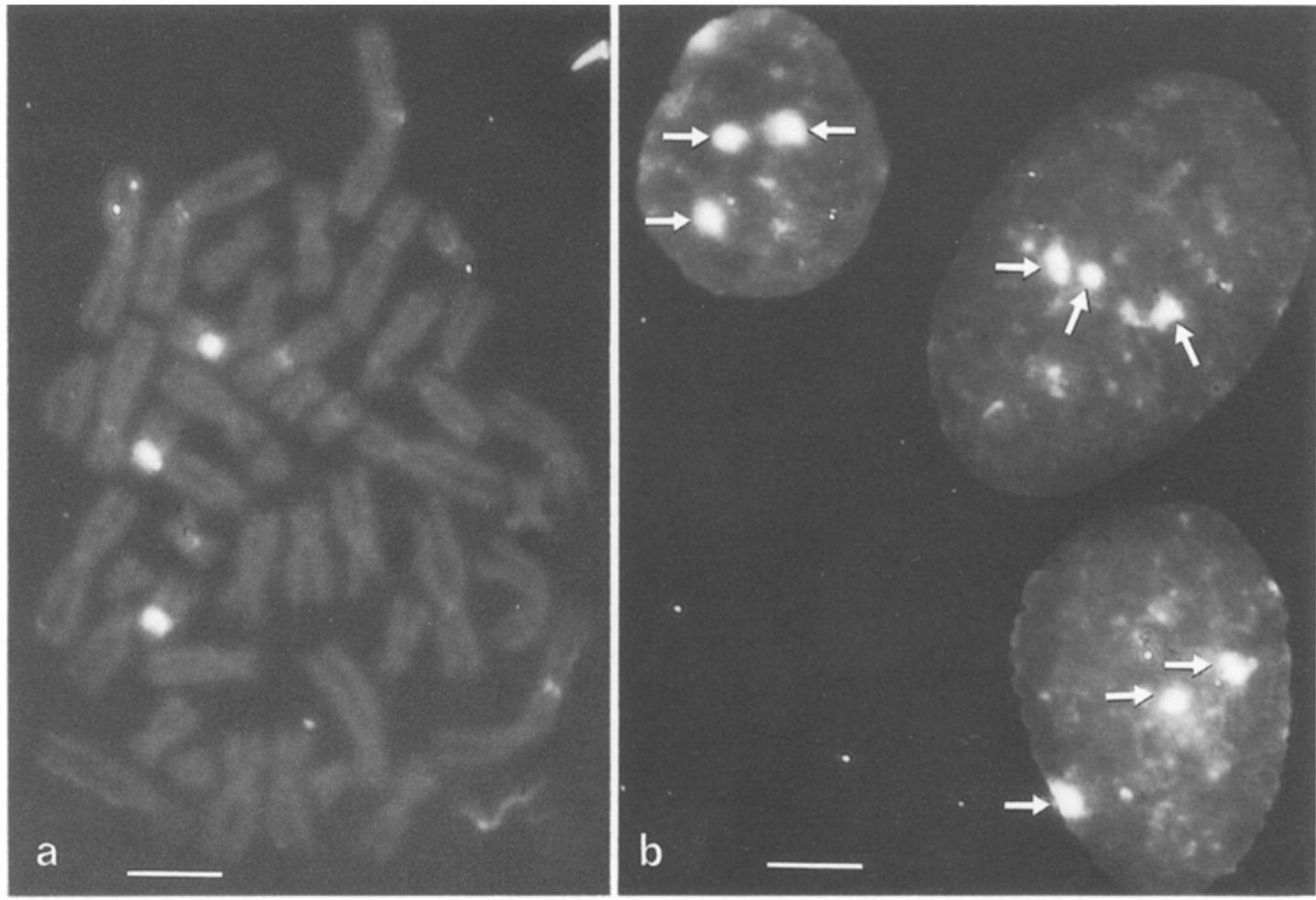

Fig.4a,b. Metaphase spread (a) and interphase nuclei (b) from an amniotic fluid cell culture with trisomy 18 as seen by reflection-contrast microscopy after in situ hybridization with AAF-labelled DNA probe L1.84 and signal detection by the immunoperoxidase method (see Materials and methods). Note intensive label over the three chromosomes 18 in the metaphase spread and three corresponding major hybridization signals over the interphase nuclei (arrows). Minor hybridization signals due to hybridization of L1.84 to the constitutive heterochromatin of other chromosomes can also be observed. The appearance of minor hybridization signals critically depends on the in situ hybridization protocol and can vary even in cells on the same slide. $\mathrm{Bar}=5 \mu \mathrm{m}$ 

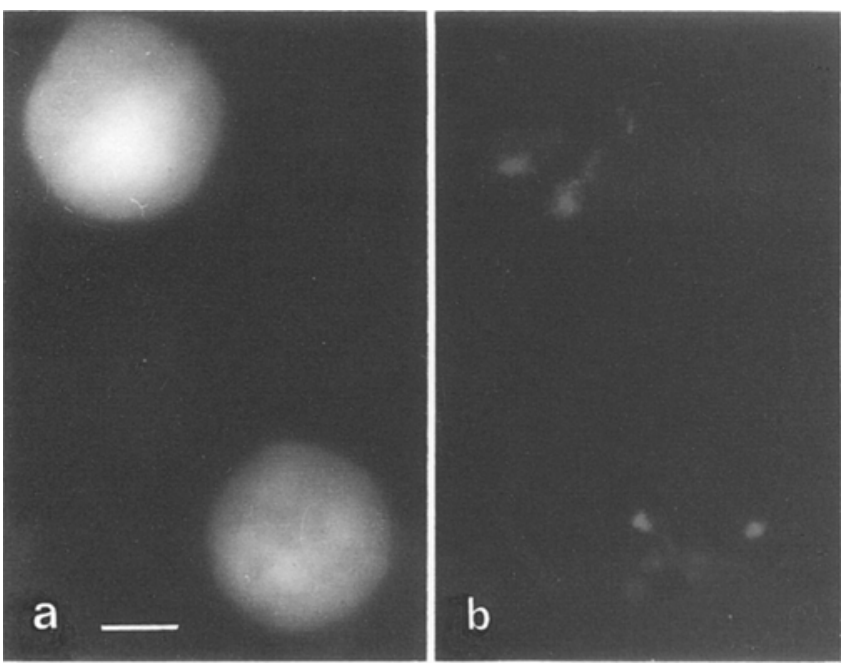

Fig.5a,b. Two interphase nuclei from a PHA-stimulated lymphocyte culture of a male individual with a normal chromosome complement $46, \mathrm{XY}$ after in situ hybridization with biotinylated DNA probe L1.84 under conditions of higher stringency (see Materials and methods, mixture I). Bar $=2.5 \mu \mathrm{m}$. a Nuclei stained with DAPI. b Visualization of the hybridization sites in these nuclei obtained by indirect immunofluorescence using a rabbit anti-biotin antibody and a FITC-goat antirabbit IgG-fraction (see Materials and methods). Specimens were photographed using a Zeiss photomicroscope equipped with epifluorescence illumination

spreads from male human lymphocytes (Figs. 1b, 2b, 7a). Accordingly, numerous intense hybridization signals were detected over interphase nuclei and it became impossible clearly to discriminate major hybridization signals from minor ones (Fig. 7b).

\section{Discussion}

The human repetitive alphoid DNA family (Devilee et al. $1986 \mathrm{a}, \mathrm{b})$ consists of long arrays of tandemly arranged monomeric units of $170 \mathrm{bp}$, and is clustered in the constitutive heterochromatin of human chromosomes ( $\mathrm{Wu}$ and Manuelidis 1980). Evidence is accumulating that the sequence heterogeneity within this family is distributed in a chromosome specific manner, so that each individual chromosome may be characterized by the presence of its own distinct alphoid DNA subfamily (Wolfe et al. 1985; Jørgensen et al. 1986). Alphoid subfamilies may display a characteristic restriction-site spacing, which would allow their detection in Southern blot experiments (Willard 1985; Jørgensen 1986; Devilee et al. 1986b). Clone L1.84 represents such a subfamily on chromosome 18 .

Cloned fragments of such subfamilies can be used for in situ hybridization experiments to label individual human chromosomes both in interphase and mitosis. The stringency of the hybridization conditions is paramount in order to avoid crosshybridization with related subfamilies present on other chromosomes. This is illustrated by the fact the L1.84 hybridizes exclusively to the centric heterochromatin of chromosome 18 under conditions of high stringency. Our data indicate that the number of chromosomes 18 present in human interphase nuclei can be reliably detected under these conditions. Evaluation of a small number of cell nuclei is sufficient to discriminate between a normal cell population and a cell population

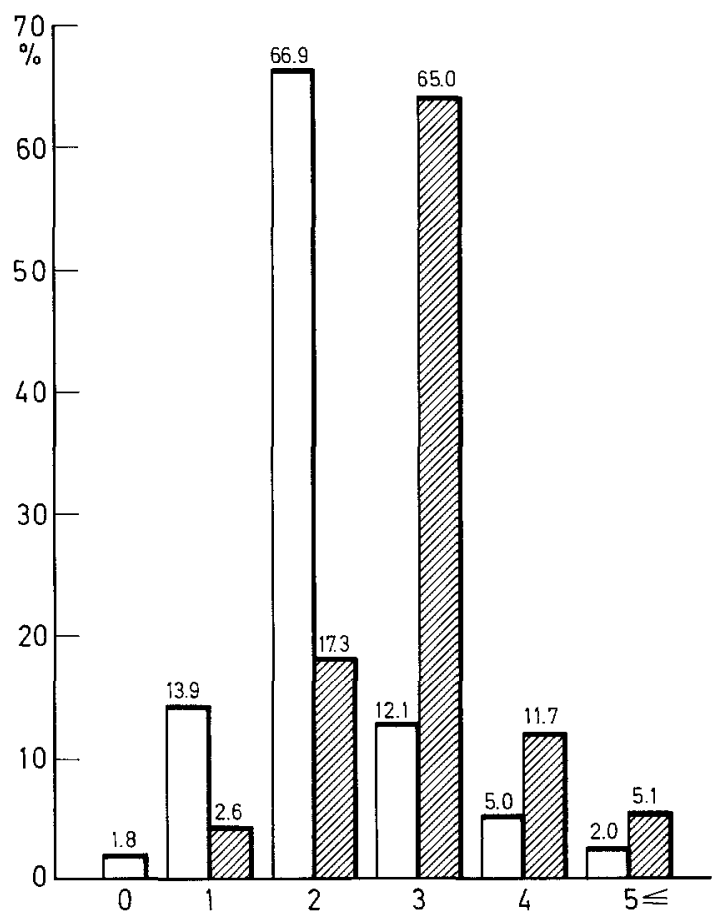

Fig. 6. Frequency distribution of major hybridization sites observed after in situ hybridization with ${ }^{3} \mathrm{H}$-labelled DNA probe $\mathrm{L} 1.84$ and autoradiography over interphase nuclei from normal amniotic fluid cells $(46, X Y)$ and amniotic fluid cells with trisomy $18(47, \mathrm{XY},+18)$. Slides with normal and trisomic cells, respectively, were hybridized under conditions of high stringency (see Materials and methods, procedure I), and further processed for autoradiography side by side. Evaluation was carried out without knowledge of the karyotype of each cell sample. Clusters of silver grains as indicated by arrows in Fig. $3 b, c$ were considered as major hybridization sites indicating the positions of chromosomes 18 in individual nuclei. Abscissa, number of major hybridization sites counted in each nucleus. Ordinate, percentage of nuclei with a given number of major hybridization sites. White columns, data obtained for diploid cells $(46, \mathrm{XY})$; number of nuclei in the evaluated sample 438. Hatched columns, data obtained for trisomic cells $(47, \mathrm{XY},+18)$; number of nuclei in the evaluated sample 623

with trisomy 18 . When the stringency is somewhat decreased, hybridization signals become apparent on a limited number of chromosomes. Besides chromosome 18 which represents the major hybridization site of L1.84 under all possible conditions of stringency, minor hybridization sites are clearly detectable over chromosomes 2, 8, 9 and 20 (Devilee et al. 1986b). After a further decrease of stringency hybridization signals become apparent over the centromeric heterochromatin of all chromosomes. Similar results have been obtained with other cloned fragments from the alphoid DNA family which show a specific hybridization to certain other individual human chromosomes under conditions of high stringency but cross-hybridize to many chromosomes under conditions of lower stringency (Willard 1985 and our unpublished observations). While further investigations of the chromosomal distribution of different distinct alphoid subfamilies and their molecular relationships are intriguing with regard to questions of chromosomal evolution in men and monkeys, their use as a diagnostic tool in "interphase cytogenetics" (see below) is limited by the fact that their occurrence seems to be largely restricted to the constitutive human heterochromatin. Furthermore, identical sequences from a given subfamily may likely occur 


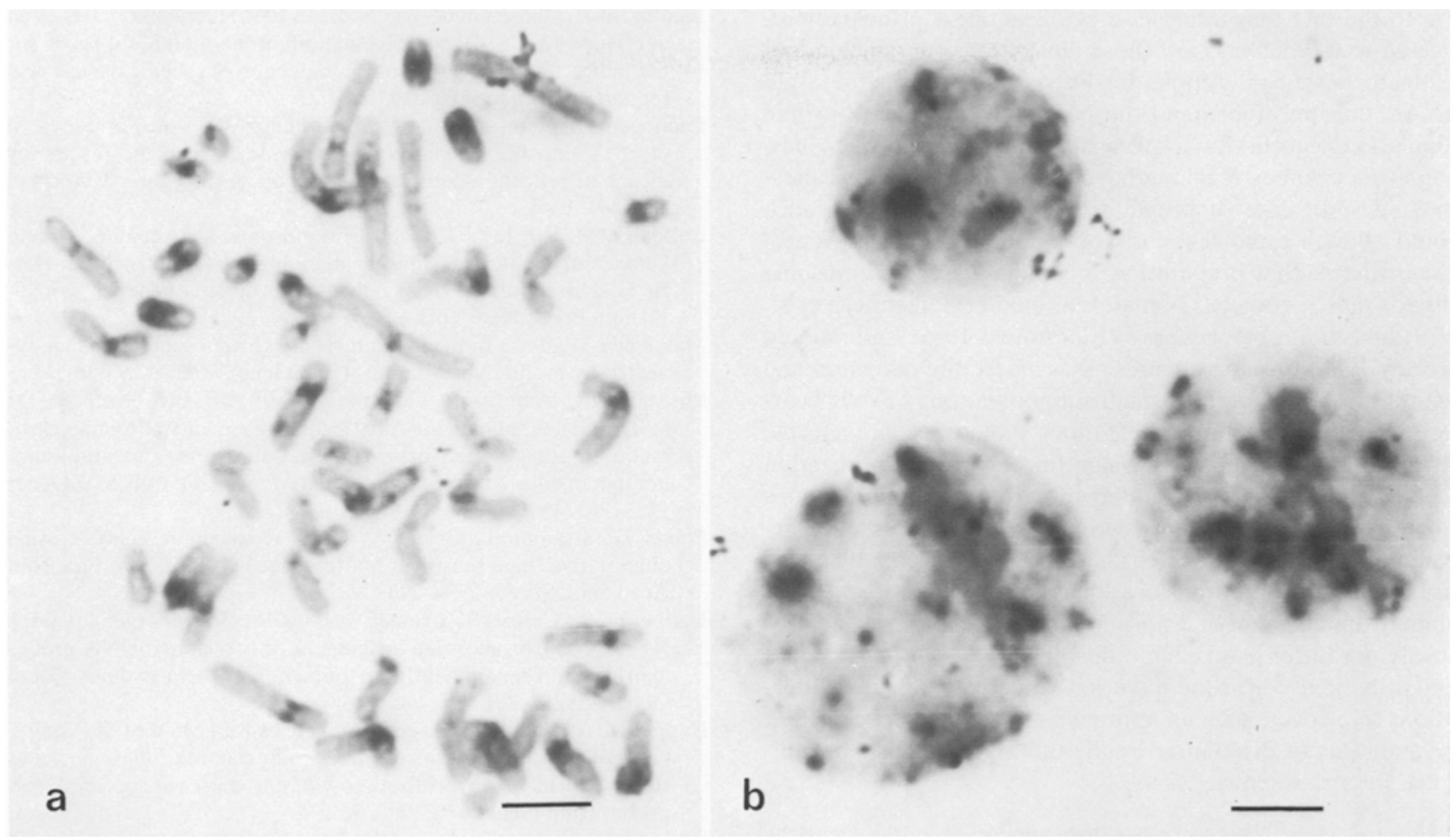

Fig. 7a,b. Lymphocytes from a male human individual $(46, \mathrm{XY})$ after in situ hybridization with biotinylated DNA probe L1.84 under conditions of low stringency (see Materials and methods, mixture II). Staining was performed by a colour reaction catalyzed by calf-alkaline phosphatase specifically coupled to the biotinylated target DNA. Note specific staining of the pericentromeric heterochromatin of the chromosome complement with varying intensity (a) and numerous corresponding spots over interphase nuclei $(\mathbf{b})$. Bar $=5 \mu \mathrm{m}$, counterstain: Giemsa

on several chromosomes and subfamilies present on different chromosomes may show a close relationship in their sequence. Accordingly, it can be difficult if not impossible for other cloned alphoid DNA sequences to make hybridization completely specific for an individual chromosome (Mitchell et al. 1986; Devilee et al. 1986b).

Alternatively, pools of single copy DNA sequences cloned from specific chromosomal subregions will provide a possibility to stain any desirable part of the chromosome complement. Double hybridization protocols with differently labelled DNA probes have been worked out for a bi-coloured detection of two target DNAs (Hopman et al. 1986) and even triple hybridization protocols might become feasible in the near future.

The possibility of staining individual chromosomal subregions by non-radioactive in situ hybridization procedures would have many applications in cytogenetics. Such applications could range from the characterization of marker chromosomes, the detection of small translocations, deletions or duplications and the definition of break points, up to the possibility of sorting chromosomes specifically labelled by fluorescence hybridization and the introduction of new banding procedures helpful for an automated karyotype analysis. In addition to mitotic chromosome complements interphase nuclei could be screened for numerical and structural aberrations such as specific chromosome translocations. The detection of a human translocation chromosome (Xqter $\rightarrow$ Xp22.2: $:$ Yq11 $\rightarrow$ Yqter) in a population of interphase nuclei has been described elsewhere (Rappold et al. 1984b). We predict that such an approach could be generalized using a strategy briefly outlined below. Our prediction is based on recent evidence indicating that not only the constitutive heterochromatin but also euchromatic parts of individual chromosomes occupy a well-defined compact volume within the nucleus (Cremer et al. 1982; Schardin et al. 1985; Manuelidis 1985) and that homologous chromosomes in human interphase nuclei occupy clearly separate domains in many cases (Rappold et al. 1984b and our unpublished data).

By using nested sets of chromosome specific DNA probes and a bi-coloured detection of two chromosomes or chromosomal subregions, one chromosome or subregion might be visualized with green the other chromosome or subregion with red fluorescence (Hopman et al. 1986). Normal interphase nuclei should present two green and two red fluorescent spots with variable distances. Consider a specific translocation between these chromosomes with breakpoints in the defined subregion of the chromosomes. We predict that interphase nuclei containing the specific translocation should bear three green and three red fluorescent spots. The distribution of each set of spots is expected to be variable depending on the presumably variable positions of the chromosomes involved. However, two green and two red spots should be detected side by side, since they mark the positions of the two translocation chromosomes. The third green and red fluorescent spot, respectively, would indicate the position of each normal homologue.

In comparison to classical cytogenetics based on the evaluation of mitotic chromosomes "interphase cytogenetics" has the obvious disadvantage that it can only be used for the confirmation or exclusion of specific aberrations. These limits are 
due to the fact that interphase cytogenetics is principally restricted to the detection of those aberrations for which an investigator specifically looks for by staining of specific target DNAs. On the other hand the possibility to screen a whole population of cells for a given aberration should open new diagnostic avenues reaching beyond the limits of classical cytogenetics. In case of prenatal diagnosis such an approach would allow a rapid diagnosis of common trisomies even in cases where the preparation of metaphase chromosome spreads fails. Fetal cells in maternal blood (Herzenberg et al. 1979) and tumor cytogenetics (Bloomfield 1985; LeBeau and Rowley 1986) provide obvious cases where the detection and quantitative evaluation of small subpopulations of cells bearing specific chromosomal aberrations should become feasible by interphase cytogenetics. Using fluorescence hybridization the detection of specific numerical chromosome aberrations can be combined with flow cytometry and fluorescence activated cell sorting (Trask et al. 1985; Pinkel et al. 1986). In case of chromosome translocations the total fluorescence obtained from aberrant and normal interphase nuclei would obviously not differ from each other, thus flow cytometry could not easily be used for the quantitative detection of such aberrations. However, such an approach appears to be well suited for quantitative evaluation by digital image analysis of individual interphase nuclei.

Acknowledgement. This work has been supported by the Deutsche Forschungsgemeinschaft.

\section{References}

Bloomfield CD (1985) The clinical significance of chromosomal changes in acute leukemia. In: Berg K (ed) Medical genetics: past, present, future. Liss, New York, pp 153-170

Cremer T, Cremer C, Baumann H, Luedtke EK, Sperling K, Teuber V, Zorn C (1982) Rabl's model of the interphase chromosome arrangement as studied by laser-UV-microbeam experiments. Hum Genet 60: 46-56

Devilee P, Slagboom P, Cornelisse CJ, Pearson PL (1986a) Sequence heterogeneity within the human alphoid repetitive DNA family. Nucleic Acids Res 14:2059-2073

Devilee P, Cremer T, Slagboom P, Bakker E, Scholl HP, Hager HD, Stevenson AFG, Cornelisse CJ, Pearson PL (1986b) Two subsets of human alphoid repetitive DNA show distinct preferential localization in the pericentromeric heterochromatin of chromosome 13, 21, 18. Cytogenet Cell Genet 41:193-201

Herzenberg LA, Bianchi DW, Schröder J, Cann HM, Iverson GM (1979) Fetal cells in the blood of pregnant woman: detection and enrichment by fluorescence activated cell sorting. Proc Natl Acad Sci USA 76:1453-1455

Hoehn H, Martin GM (1973) Nonrandom arrangement of human chromatin: topography of disomic markers $\mathrm{X}, \mathrm{Y}$, and $1 \mathrm{~h}^{+}$. Cytogenet Cell Genet 12:443-452

Hopman AHN, Wiegant J, Duijn P van (1986) A new hybridocytochemical method based on mercurated nucleic acid probes and sulfhydryl-hapten ligands. I. Stability of the mercury-sulfhydryl bond and influence of the ligand structure on immunochemical detection of the hapten. Histochemistry $84: 169-178$

Jørgensen AL, Bostock CJ, Bak AL (1986) Chromosome-specific subfamilies within human alphoid repetitive DNA. J Mol Biol $187: 185-196$
Landegent JE, Jansen in de Wal N, Baan RA, Hoeijmakers JHJ, Van der Ploeg M (1984) 2-Acetylaminofluorene-modified probes for the indirect hybridocytochemical detection of specific nucleic acid sequences. Exp Cell Res 153:61-72

Landegent JE, Jansen in de Wal N, Ploem JS, Van der Ploeg M (1985) Sensitive detection of hybridocytochemical results by means of reflection-contrast microscopy. J Histochem Cytochem $33: 1241-1246$

LeBeau MM, Rowley JD (1986) Chromosomal abnormalities in leukemia and lymphoma: clinical and biological significance. In: Harris $\mathrm{H}$, Hirschhorn $\mathrm{K}$ (eds) Advances in human genetics, vol 15 . Plenum Press, New York

Manuelidis L (1985) Individual interphase chromosome domains, revealed by in situ hybridization. Hum Genet $71: 288-293$

Mitchell AR, Ambros P, Gosden JR, Morten JEN, Porteous DJ (1986) Gene mapping and physical arrangements of human chromatin in transformed hybrid cells: fluorescent and autoradiographic in situ hybridization compared. Somatic Cell Mol Genet $12: 313-324$

Pinkel D, Straume T, Gray JW (1986) Cytogenetic analysis using quantitative, high sensitive, fluorescence hybridization. Proc Natl Acad Sci USA 83:2934-2938

Rappold GA, Cremer T, Cremer C, Back W, Bogenberger J, Cooke HJ (1984a) Chromosome assignment of two cloned DNA probes hybridizing predominantly to human sex chromosomes. Hum Genet $65: 257-261$

Rappold GA, Cremer T, Hager HD, Davies KE, Müller CR, Yang T (1984b) Sex chromosome positions in human interphase nuclei as studied by in situ hybridization with chromosome specific DNA probe. Hum Genet 67:317-325

Schardin M, Cremer T, Hager HD, Lang M (1985) Specific staining of human chromosomes in Chinese hamster $\times$ man hybrid cell lines demonstrates interphase chromosome territories. Hum Genet 71: 281-287

Schempp W, Meer B (1983) Cytologic evidence for three human Xchromosomal segments escaping inactivation. Hum Genet 63: 171-174

Schmid M, Poppen A, Schmid W, Engel W (1981) Somatic pairings of the $\mathrm{Y}$ heterochromatin in human XYY and XYqi cells. Cytogenet Cell Genet 29:203-297

Spaeter M (1975) Nichtzufällige Verteilung homologer Chromosomen (Nr.9 und XY) in Interphasekernen menschlicher Fibroblasten. Hum Genet 27:111-118

Trask B, Van den Engh G, Landegent J, Jansen in de Wal N, Van der Ploeg M (1985) Detection of DNA sequences in nuclei in suspension by in situ hybridization and dual beam flow cytometry. Science 230:1401-1403

Willard HF (1985) Chromosome specific organization of human alpha satellite DNA. Am J Hum Genet 37:524-532

Wolfe J, Darling SM, Erickson RP, Craig IW, Buckle VJ, Rigby PWJ, Willard HF, Goodfellow PN (1985) Isolation and characterization of an alphoid centromeric repeat family from the human Y chromosome. J Mol Biol 182:477-485

$\mathrm{Wu}$ JC, Manuelidis L (1980) Sequence definition and organization of a human repeated DNA. J Mol Biol 142:363-386

Zabel BU, Naylor SL, Sakaguchi AY, Bell GI, Shows TB (1983) High-resolution chromosomal localization of human genes for amylase, proopiomelanocortin, somatostatin, and a DNA fragment (D3S1) by in situ hybridization. Proc Natl Acad Sci USA $80: 6932-6936$

Received June 2, 1986 